\title{
Polymyalgia rheumatica and corticosteroids: how much for how long?
}

\author{
A. R. BEHN, T. PERERA, AND A.B. MYLES \\ From the Department of Rheumatology, St Peter's Hospital, Chertsey, Surrey
}

SUMMARY In a prospective study of 176 patients in whom polymyalgia rheumatica (PMR) or giant cell arteritis (GCA) had been diagnosed between 1968 and 1980 the effect of corticosteroid treatment was studied. In those with PMR alone an initial regimen of $10 \mathrm{mg}$ prednisolone daily and for the majority of those with GCA $20 \mathrm{mg}$ daily were adequate to control symptoms. No patient suffered a serious disease complication after starting treatment. Regular follow-up enabled the minimum effective corticosteroid dose to be used. Complications of treatment were infrequent. Corticosteroid treatment has been withdrawn from 72 patients after a mean of 31 months treatment (range 3-103 months). Thirty subsequently relapsed, all within 21 months of withdrawal. No clinical feature predicted those who were more likely to relapse. No rigid treatment schedule should be used in these diseases.

Polymyalgia rheumatica (PMR) is a well recognised clinical syndrome occurring usually in patients over the age of 55 years, who experience pain and incapacitating morning stiffness in the shoulder and pelvic girdles associated with variable systemic symptoms and a raised erythrocyte sedimentation rate (ESR). The underlying pathological abnormality in PMR is not known, although the association with giant cell arteritis (GCA) is well established; up to $40 \%$ of patients with symptoms of PMR have arteritis in temporal artery biopsy specimens. ${ }^{1}$ Occult GCA could therefore be present in all or there could be more than one cause of PMR. Inflammatory arthritis occurs in some cases of PMR ${ }^{2}$ and GCA.

Despite the risk of serious side effects most clinicians give corticosteroid treatment for patients with PMR, and this is considered mandatory if there is evidence of GCA. There is no evidence that corticosteroids reduce the duration of the disease. ${ }^{3}$ The usual starting dose for those with PMR alone is $10-20 \mathrm{mg}$ prednisolone daily and for the patients with evidence of GCA 40-60 mg daily. Differences of opinion arise in deciding the initial regimen for patients with symptoms of PMR alone who have a positive arterial biopsy. Should these patients be treated with the higher doses of corticosteroids? Serious corticosteroid side effects do occur, particularly in those with GCA started on higher doses. ${ }^{4-7}$ The problem therefore is in deciding on the initial dose and for how long treatment should continue. ${ }^{8}$

Accepted for publication 12 July 1982.

Correspondence to Dr A. R. Behn, Department of Rheumatology, St Luke's Hospital, Warren Road, Guildford, Surrey GU1 3NT.
In this prospective study of 199 patients we have examined the course of the disease with particular reference to dosage and duration of corticosteroid treatment. Complications of the disease and its treatment have been assessed.

\section{Patients and methods}

Between 1968 and 1980 all patients initially diagnosed as PMR or GCA in the Rheumatology Department of St Peter's Hospital, Chertsey, were followed up in a prospective clinical study.

Criteria for diagnosis of PMR were pain and stiffness in girdle and spinal muscles for at least 2 months, prolonged morning stiffness, absence of signs or laboratory evidence of polyarthritis or muscle disease, raised ESR, and good response to corticosteroids. Criteria for a clinical diagnosis of GCA were severe temporal or occipital pain or jaw claudication, tender temporal arteries or absent temporal pulses, a raised ESR, and a good response to corticosteroids.

Temporal artery biopsy was done in some patients with symptoms of PMR alone and in the majority of patients with a clinical diagnosis of GCA alone or in combination with PMR. In this study patients with symptoms of PMR alone and a positive arterial biospy were not placed in the group with combined PMR and GCA unless there was clinical evidence of arteritis.

The following investigations were done in all patients at initial presentation: haemoglobin, white cell count, ESR, urea, electrolytes, alkaline phosphatase, plasma proteins and serum electrophoretic 
strip, creatine kinase, autoimmune profile, and radiographs of the chest and pelvis.

Patients were followed up at monthly intervals. Diagnosis of a relapse was made on recurrence of the original symptoms, usually but not always accompanied by a rise in ESR. A rising ESR without symptoms was not considered sufficient evidence of relapse.

The cause of death was established from death certificates or post-mortem examination.

\section{Results}

In the study period 199 patients were initially diagnosed as PMR or GCA. Follow-up showed that 17 were incorrectly diagnosed (polyarthritis 12 , no subsequent diagnosis 2, spondylitis 1 , osteoarthritis 1 , myeloma 1). The study group consisted of 182 patients ( 134 women, 48 men). The presenting age ranged from 47 to 90 years (mean 69 years). A clinical diagnosis of PMR was made in 114 patients, of GCA alone in 21 patients, and of mixed PMR and GCA in 47 patients. The erythrocyte sedimentation rate at time of diagnosis ranged from $13 \mathrm{~mm}$ to 125 $\mathrm{mm}$ (mean $66 \mathrm{~mm}$ ) in one hour.

Results of temporal artery biopsy are shown in Table 1. Ten patients experienced visual symptoms at their first attendance. 2 suffering permanent visual loss.

TREATMENT REGIMENS

Corticosteroids in the form of prednisolone were used to treat 176 patients. Different regimens were used. The most frequent starting dose for those with a clinical diagnosis of PMR alone was $10 \mathrm{mg}$ daily regardless of biopsy findings and for those with a clinical diagnosis of GCA was $20 \mathrm{mg}$ daily (Table 2). Six of those with visual symptoms at presentation were started on 30-60 mg prednisolone daily, and some patients with PMR started 5-9 mg daily. The corticosteroid dose was regulated with an aim of keeping the patient's symptoms suppressed and the ESR below $30 \mathrm{~mm} / \mathrm{h}$. When this was achieved, the dose of prednisolone was decreased by $1 \mathrm{mg}$ at monthly intervals for those receiving $10 \mathrm{mg}$ a day or less. In those taking higher doses the initial reduction

Table 1 Temporal artery biopsy

\begin{tabular}{llcc}
\hline Clinical diagnosis & Positive & Negative & Not done \\
\hline PMR & 11 & 44 & 59 \\
GCA & 10 & 5 & 6 \\
PMR/GCA & 15 & 20 & 12 \\
Total (182) & 36 & 69 & 77 \\
\hline
\end{tabular}

Table 2 Treatment regimens in 182 patients

\begin{tabular}{lccc}
\hline $\begin{array}{l}\text { lnitial dose } \\
\text { prednisolone mg/day }\end{array}$ & $P M R$ & $P M R / G C A$ & $G C A$ \\
\hline $5-9$ & $33(11)^{*}$ & $3(3)$ & \\
10 & $67(8)$ & $16(5)$ & $2(2)$ \\
$11-20$ & 4 & $23(1)$ & 10 \\
$21-60$ & 4 & 5 & 9 \\
$\begin{array}{l}\text { Nonsteroidal } \\
\quad \text { anti-inflammatory drugs }\end{array}$ & 6 & & \\
Total & 114 & 47 & 21 \\
\hline
\end{tabular}

${ }^{*}$ Figures in parentheses represent the number of patients subsequently needing an increase in prednisolone dosage.

was more rapid as long as the symptoms remained in remission.

Of those with a clinical diagnosis of PMR alone, starting on $10 \mathrm{mg}$ prednisolone daily, fewer needed an increase in dose to control symptoms than those starting on less than $10 \mathrm{mg}$ daily ( $\chi^{2}$ with Yates's correction $=5 \cdot 3, p<0 \cdot 025)$. Of those with a clinical diagnosis of GCA starting on $20 \mathrm{mg}$ prednisolone daily fewer needed an increase in dose to control symptoms than those starting on $10 \mathrm{mg}$ or less $\left(\chi^{2}\right.$ with Yates's correction $=13 \cdot 1, \mathrm{p}<0 \cdot 001)$. Only 7 patients with PMR alone, 5 with mixed PMR/GCA, and 8 with GCA alone required daily doses of prednisolone in excess of $10 \mathrm{mg}$ for longer than one year.

Corticosteroids have been withdrawn from 72 patients after a mean of 31 months of treatment (range 3-103 months), of whom 30 relapsed (Fig. 1). All relapses occurred within 21 months of withdrawal. There was no significant difference in the mean length of pretreatment symptoms, duration of treatment, starting dose of prednisolone, initial ESR, or haemoglobin between 19 patients with PMR alone who relapsed and 17 who had been off treatment longer than 2 years (Table 3 ). Similarly there were no significant differences between 11 patients with GCA who relapsed and 8 who had been off treatment longer than 2 years (Table 3 ).

Second and even third attempts at withdrawal were made in 12 of the 30 patients who had relapsed at the initial attempt, of whom 8 remain in remission. Ninety-three patients still need corticosteroids; 5 have required treatment for longer than 10 years.

Six patients were not given corticosteroid treatment. They were all seen early on in the study period. In 3 cases the patients and their family doctors gave a consistent story of polymyalgia rheumatica over a period of months associated with a raised ESR. However, symptoms, signs, and ESR were settling by the time they attended and continued to do so without additional treatment. In 3 others with PMR alone the use of nonsteroidal 

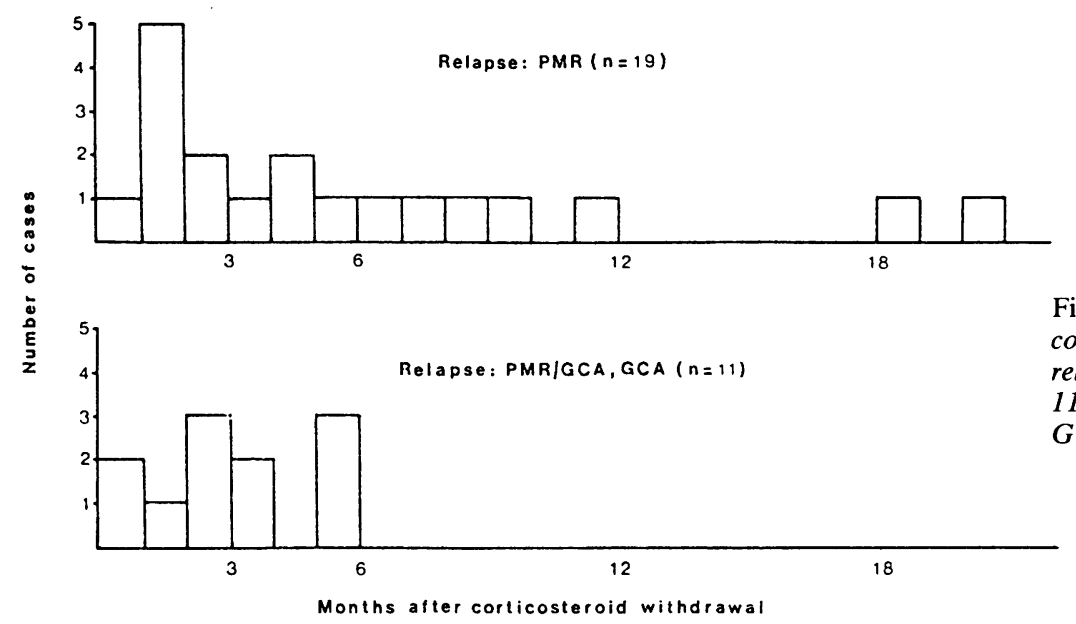

Fig. 1 Interval (months) between corticosteroid withdrawal and relapse in 19 patients with $P M R$ and 11 patients with $P M R / G C A$ or GCA.

Table 3 Comparison of patients relapsing and those in prolonged remission after corticosteroid withdrawal

\begin{tabular}{|c|c|c|c|c|c|c|}
\hline & \multicolumn{2}{|c|}{ Remission $>2$ years } & \multicolumn{4}{|c|}{ Relapse } \\
\hline & $P M R$ & $G C A \pm P M R$ & $P M R$ & $p^{*}$ & $G C A \pm P M R$ & $p^{*}$ \\
\hline $\begin{array}{l}\text { Number of patients } \\
\text { Mean duration of symptoms }\end{array}$ & 17 & 8 & 19 & & 11 & \\
\hline $\begin{array}{l}\text { before treatment (months) } \\
\text { Mean duration of }\end{array}$ & $4 \cdot 1$ & $6 \cdot 7$ & $2 \cdot 9$ & NS & $5 \cdot 3$ & NS \\
\hline $\begin{array}{l}\text { Mean starting dose of } \\
\text { prednisolone (mg/day) }\end{array}$ & 8.9 & $17 \cdot 2$ & $9 \cdot 5$ & NS & $17 \cdot 3$ & NS \\
\hline
\end{tabular}

*Student's $t$ test. NS $=\mathrm{p}>0.05$.

anti-inflammatory drugs had provided good relief from symptoms. None of these patients has relapsed.

Seven patients have been lost to follow-up.

\section{COMPLICATIONS OF THE DISEASE}

Ten patients presented with visual symptoms (uniocular blindness 2; partial uniocular visual loss 1; unilateral amaurosis fugax 2 ; transient blurring of vision 5). Four patients originally diagnosed as PMR alone subsequently developed symptoms of GCA 2 , 6,8 , and 22 months after corticosteroid treatment had been started, of whom 2 had a positive temporal artery biopsy. None of these or any other patient suffered permanent visual loss after starting corticosteroids.

\section{DEATHS}

Thirty-one patients died during the study period. The causes of death were myocardial infarction or ischaemic heart disease (13 cases), malignancy (5 cases), bronchopneumonia ( 5 cases), cerebrovascular accident (3 cases), suicide (1), pulmonary embolus (1), postoperative peritonitis (1), congestive cardiomyopathy (1), and rupture of the ascending aorta (1).

Necropsy was carried out in 5 of these patients. The patient who died from a ruptured ascending aorta had severe atheroma of cerebral and coronary vessels, but no histological studies were available. She had been taking prednisolone $7 \mathrm{mg}$ daily 7 years after the original diagnosis of PMR. One patient committed suicide after 6 months of successful treatment for PMR and was taking $6 \mathrm{mg}$ prednisolone daily.

Acknowledging that many of the patients that died did not have post-mortem examinations, we have no evidence that arteritis or corticosteroid treatment directly contributed to the cause of death. The number of deaths from ischaemic cardiac or cerebral disease was compatible with the age of the group under study.

\section{COMPLICATIONS OF TREATMENT}

Possible complications of treatment are shown in Table 4. All those developing symptomatic vertebral osteoporosis were women. After a period of back 
Table 4 Possible complications of corticosteroid treatment in 176 patients

\begin{tabular}{ll}
\hline Vertebral osteoporosis & 9 \\
Herpes zoster & 7 \\
Cataracts & 5 \\
Diabetes & 2 \\
Fractured femur & 2 \\
Possible ischaemic necrosis of hip & 1 \\
Septic arthritis & 1 \\
\hline
\end{tabular}

pain they all became virtually free of symptoms and only one patient experienced recurrent symptoms. None of the cataracts were of the posterior subcapsular type usually associated with systemic corticosteroid treatment. Septic arthritis occurred in an interphalangeal joint of an 84-year-old woman taking $7.5 \mathrm{mg}$ prednisolone daily for GCA diagnosed 6 years before.

\section{Discussion}

If all cases of PMR alone are a manifestation of GCA, then all such patients may be at risk from the known complications of GCA and perhaps should be treated with the higher doses of corticosteroids as recommended by some authors, ${ }^{19}$ but the increased risk of side effects from treatment needs consideration. Unfortunately a negative temporal artery biopsy does not resolve the situation, because skip lesions occur. ${ }^{10}$ More recent opinion has favoured a smaller initial dose (10-20 mg prednisolone daily) to control symptoms in those with a clinical diagnosis of PMR alone. ${ }^{411}{ }^{12}$ From our experience an initial dose of 10 mg prednisolone daily is adequate to suppress symptoms for most of the patients with PMR alone; few required higher doses. A single morning dose is just as effective as a nocturnal dose, has a less suppressive effect on adrenal function, and causes less nocturia. ${ }^{13}$ Although 4 out of 114 of our patients with PMR developed symptoms and signs of GCA while taking small doses of prednisolone, none of these suffered permanent visual loss during follow-up. This low level of risk agrees with the finding of Spiera and Davison $^{4}$ but contrasts with a recent report of 5 out of 66 patients presenting with PMR alone suffering probable complications of arteritis while taking small doses of corticosteroid.$^{14}$ Some clinicians recommend the use of nonsteroidal anti-inflammatory drugs for PMR provided arterial biopsy is negative. ${ }^{2}$ Although 6 of our patients were similarly treated, they were seen early in the study period, and it is not now our practice to withhold corticosteroids, because they provide much more effective relief of symptoms and appear to avert serious ocular complications.
There is disagreement over the dose of corticosteroids used to treat patients with symptomatic GCA with or without concurrent PMR. Studies established the value of corticosteroids in reducing the incidence of blindness. ${ }^{15}{ }^{16}$ The initial doses used varied from 10 to $50 \mathrm{mg}$ prednisolone and 100 to $300 \mathrm{mg}$ cortisone daily. Paulley et al. ${ }^{17}$ found prednisolone $20 \mathrm{mg}$ daily effective and only occasionally found it necessary to use larger doses. Recent recommendations on starting treatment, however, have emphasised total daily doses of prednisolone around $60 \mathrm{mg} \cdot{ }^{5-718}$ Despite the intention of reducing dosage over a few weeks or months it is inevitable that some patients remain on relatively high maintenance doses $(10 \mathrm{mg}$ prednisolone or greater), perhaps unnecessarily. ${ }^{7}$ Although there is a clinical impression that larger doses of corticosteroid are needed to control the symptoms and signs of GCA than for PMR alone, there is no evidence that $60 \mathrm{mg}$ of prednisolone daily as an initial dose is any better than $20 \mathrm{mg}$ in preventing complications of GCA. In patients treated with large doses of corticosteroids further visual loss has occurred after starting treatment. ${ }^{19}$ Corticosteroids probably have complex effects on coagulation and have been shown to inhibit the synthesis of prostacyclin..$^{20}$ Topical and occasionally high-dose systemic corticosteroids may cause an increase in intraocular pressure. ${ }^{21}$ Perhaps high doses occasionally have a deleterious effect on a critical vascular state. Corticosteroids are thought to be a possible cause of necrotising arteritis in patients with rheumatoid arthritis treated with high doses. ${ }^{22}$ This speculative suggestion highlights the uncertain mechanism by which corticosteroids protect against visual loss. Repeat biopsies during and after treatment and long after clinical signs and symptoms have disappeared sometimes show an active arteritis. ${ }^{1} \mathrm{We}$ believe our experience provides evidence that a starting dose of $20 \mathrm{mg}$ prednisolone daily is adequate for most patients with GCA and may avoid more prolonged periods at higher dosage.

An early study of PMR before corticosteroids were used in treatment suggested wide variation in duration of the disease, with a mean of 7 years..$^{23}$ There have been suggestions that treatment is usually necessary for only 2 to 3 years $^{519}$ and that relapse after stopping treatment is rare. ${ }^{24}$ Our patients have shown a wider variation in duration of treatment necessary to suppress symptoms, which presumably reflects the period of active disease and agrees with the experience of others. ${ }^{25-27}$ Relapse after corticosteroid withdrawal was common in our patients, and it was not possible to find a clinical feature that would identify those at risk. We suggest that patients are followed up for at least 2 years after corticosteroid withdrawal, with particular attention to symptoms. Balanced against the relief of symptoms and 
prevention of serious complications, the incidence of possible corticosteroid side effects has been acceptably small.

We believe that regular and personal follow-up of patients makes possible the use of the minimum effective dose of corticosteroids, and no exact schedule of duration of treatment should be recommended.

\section{References}

1 Fauchald P, Rygvold O, Oystese B, Temporal arteritis and polymyalgia rheumatica. Clinical and biopsy findings. Ann Intern Med 1972; 77: 845-52.

2 O'Duffy J D, Hunder G G, Wahner H W. A follow-up study of polymyalgia rheumatica: evidence of chronic axial synovitis. J Rheumatol 1980; 7: 685-93.

3 Mowat A G, Hazleman B L. Polymyalgia rheumatica-a clinical study with particular reference to arterial disease. $J$ Rheumatol 1974; 1: 190-202.

4 Spiera H, Davison S. Long term follow up of polymyalgia rheumatica. Mt Sinai J Med NY 1978; 45: 225-9.

5 Huston K A, Hunder G G, Lie J T, Kennedy R H, Elveback L R. Temporal arteritis. A 25 year epidemiologic, clinical and pathological study. Ann Intern Med 1978; 88: 162-7.

6 Fainaru M, Friedman G, Friedman B. Temporal arteritis in Israel. A review of 47 patients. J Rheumatol 1979; 6: 330-5.

7 Graham E, Holland A Avery A, Russell R W R. Prognosis in giant-cell arteritis. $\mathrm{Br}$ Med J 1981; 282: 269-71.

8 Anonymous. Steroids in polymyalgia rheumatica. Lancet 1979 ; ii: 341 .

9 Hamilton C R, Shelley W M, Tumulty P A. Giant cell arteritis: including temporal arteritis and polymyalgia rheumatica. Medicine (Baltimore) 1971; 50: 1-27.

10 Klein R G, Campbell R J, Hunder G G, Carney J A. Skip lesions in temporal arteritis. Mayo Clin Proc 1976; 51: 504-10.

11 Myles A B. Polymyalgia rheumatica and giant cell arteritis: a seven year survey. Rheumatol Rehabil 1975; 14: 231-5.
12 Mowat A G. Generalised rheumatism: polymyalgia rheumatica and its differential diagnosis. Clin Rheum Dis 1979; 5: 775-95.

13 Myles A B, Doherty S M. Morning dose prednisolone treatment of patients with polymyalgia rheumatica. Abstracts IXth European Congress of Rheumatology. 1979: 1046.

14 Jones J G, Hazelman B L. Prognosis and management of polymyalgia rheumatica. Ann Rheum Dis 1981; 40: 1-5.

15 Birkhead N C, Wagener H P, Shick R M. Treatment of temporal arteritis with adrenal corticosteroids. JAMA 1957; 163: $821-7$

16 Russel R W R. Giant cell arteritis. A review of 35 cases. $Q J$ Med 1959; 28: 471-89.

17 Paulley J W, Hughes J P. Giant cell arteritis or arteritis of the aged. Br Med J 1960; ii: 1562-7.

18 Anonymous. Ocular complications of temporal arteritis. $\mathrm{Br}$ Med J 1979; i: 1443 .

19 Meadows S P. Temporal or giant cell arteritis. $J R$ Soc Med 1966; 59: 329-33.

20 Blajchman M/A, Senyi A F, Hirsh J, Surya Y, Buchanan M, Mustard J F. Shortening of the bleeding time in rabbits by hydrocortisone caused by inhibition of prostacyclin generation by the vessel wall. J Clin Invest 1979; 63: 1026-35.

21 David D S, Berkowitz J S. Ocular effects of topical and systemic corticosteroids. Lancet 1969; ii: 149-51.

22 Schmid F R, Cooper N S, Ziff M, McEwen C. Arteritis in rhe umatoid arthritis. Am J Med 1961; 30: 56-83.

23 Bagratuni L. Prognosis in the anarthritic rheumatoid syndrome. Br Med J 1963; i: 513-8.

24 Huskisson E C. Routine drug treatment of rheumatoid arthritis and other rheumatic diseases. Clin Rheum Dis 1979; 5: $697-706$.

25 Coomes E N, Ellis R M, Kay A G. A prospective study of 102 patients with the polymyalgia rheumatica syndrome. Rheumatol Rehabil 1976; 15: 270-6.

26 Von Knorring J. Treatment and prognosis in polymyalgia rheumatica and temporal arteritis. Acta Med Scand 1979; 205: 429-35.

27 Fernandez-Herlihy L. Duration of corticosteroid therapy in GCA.J Rheumatol 1980; 7: 361-4. 